\title{
Peligros, remedios y justificaciones en el arte de traducir en el siglo XVIII. El caso de Ignacio García Malo
}

\author{
FELIPE RODRÍGUEZ MORÍN \\ Instituto Feijoo de Estudios del Siglo XVIII, (Universidad de Oviedo) \\ felipe.rodriguezmorin@asturias.org
}

Recibido: 29 de mayo de 2014

Aceptado: 23 de marzo de 2015

\section{RESUMEN}

La actividad de traducir a fines del siglo XVIII producía bastantes suspicacias entre las capas más ilustradas de la sociedad, especialmente a causa de las frecuentes torpezas y dislates cometidos en el ámbito lingüístico. Por tal motivo, un escritor celoso de su reputación literaria, como era el caso de Ignacio García Malo, intentará desmarcarse de toda aquella plaga de incompetentes corruptores del idioma, mediante la proclama de que sus traducciones, fruto de la cualificación y del esfuerzo a ellas dedicado, resultarán útiles a la nación. Sin embargo, no estamos muy convencidos de que la puridad de la que se vanagloria en cuanto a la utilización de neologismos la acabara plasmando en la práctica, sobre todo en lo que se refiere a giros y expresiones procedentes del francés.

Palabras clave: García Malo, lengua, traducción, galicismos, utilidad pública.

Dangers, solutions and justifications in the art of translation in the $18^{\text {th }}$ century. Ignacio García Malo's case

\begin{abstract}
The art of translation at the end of the $18^{\text {th }}$ century generated quite a lot of suspicions among the most erudite layers of the society, particularly because of the frequent mistakes made in the linguistic field. For that reason, a writer who is very conscientious regarding his literary reputation, as was the case with Ignacio García Malo, will try to dissociate himself from that plague of incompetent corrupters of language, by proclaiming that his translations, which are a result of the qualification and the effort devoted to them, will be useful for the nation. However, we are not very convinced that he will put into practice the orthodoxy he boasts about the use of neologisms, especially as regards to French expressions and terms.
\end{abstract}


Keywords: García Malo, language, translation, Gallicisms, public utility.

Sumario: 1. El controvertido oficio de traductor en la España de finales del XVIII. 2. Calidad y servicio a la sociedad como pretextos para traducir. 3. Teoría frente a práctica en la introducción de neologismos. 4. Conclusión.

\section{El controvertido oficio de traductor en la España de finales del XVIII}

Particulares circunstancias, propias de la época, confluyen en el siglo ilustrado muy a propósito para que en él florezca el arte de la traducción ${ }^{1}$. Sin embargo, a pesar de ello, la figura del traductor no parecía resultar, en términos generales, símbolo de reputación y buen crédito literario. Es más, había quien pensaba, caso de Vargas y Ponce, que este ramo de las bellas letras era especialmente apropiado para escritores perezosos: "El hombre odia el trabajo por naturaleza, y ni aun pensar quiere quando sabe que otro ha pensado por él. Por eso há medio siglo que España alimenta sus prensas con pensamientos agenos, y que se ha vuelto una Nacion de Traductores $^{2} "$ (1793: 179).

Y como la apatía en el discurrir fácilmente y a menudo lleva como de la mano la dejadez en el aprender, el resultado final solía propiciar una excesiva profusión de gentes de nula cualificación, metidas a trasplantar libros extranjeros a nuestro idioma solo para lograr beneficios económicos. Tal comportamiento no puede provocar más que el enojo en personas a quienes sí que les importa, y mucho, el buen uso del castellano, como le ocurre a Forner (1967:155-156), que protesta porque los malos traductores descuidan la expresión al introducir locuciones y modismos sin sentido en la lengua castellana ${ }^{3}$.

Esa nesciencia y desidia por instruirse precipitaba a muchos traductores por el abismo del desatino censurado por Cadalso, tal cual era el de la inevitable importación masiva de neologismos, típico defecto a dichas carencias adherido: "Como no saben su propia lengua [...], cuando se hallan con una hermosura en algún original francés, inglés o italiano, amontonan galicismos, italianismos y anglicismos ${ }^{4 ”}$ (1952: 158).

1 Lafarga lo explica así: "El siglo XVIII es una etapa de efervescencia de la actividad traductora. La multiplicación de las relaciones culturales, la cada vez mayor facilidad (aun teniendo en cuenta todas las limitaciones) de acceso a las lenguas extranjeras, con el consiguiente aumento en número y calidad de las herramientas de aprendizaje y uso, como gramáticas y diccionarios, el ansia misma de ampliar los conocimientos y el saber, tan propia del espíritu ilustrado, todo ello favorecía el auge de la traducción" (Lafarga 1997: 37). De semejante modo se expresa también Étienvre (2006: 93).

2 Ha de recordarse, al efecto, la aclaración de François López: "En el siglo XVIII y en los anteriores una obra traducida deja de ser propiedad intelectual de su autor fuera de su país y pasa a serlo (si se pide licencia y, más aún, privilegio) del traductor" (1990: 307).

3 A este respecto, ha de significarse que el temor a la multiplicación de términos o giros foráneos se va a centrar de manera especial en los provenientes de Francia; así afirma Étienvre que: "L'inquiétude suscitée en Espagne, au XVIIIème siècle, par la prolifération des gallicismes est aisément perceptible” (1996: 99).

4 Por eso, con toda razón puede decir Lázaro Carreter que "Los traductores eran, sin duda, los más irresponsables introductores de neologismos" (1985: 276). 
A veces, la degradación llegaba a alcanzar tan notables proporciones que es padecida incluso con sentimiento y aflicción personal, como le ocurre a Trigueros: "Quebrántase el corazon al ver tan maltratada la lengua castellana, y causa bascas el oir un lenguaje empedrado de voces y modismos de tutilimundi, sin conservar ni aun la sintasîs" (t. I, 1804: XII).

Todo este ambiente debía causar, en el fondo, una significativa presión en el escritor celoso de su fama que se decidiera a poner en castellano un libro foráneo; de ahí que en muchos casos se comiencen este tipo de obras con proemios exculpatorios, como es el caso de Bernardo María de Calzada quien, para ganarse la indulgencia del lector, subraya lo dificultoso del empeño, así como los beneficios sociales que su empresa habría de reportar. Argumentos ambos de los que echarán también mano otros muchos escritores para justificar su labor, entre ellos García Malo, como más adelante veremos. Pero oigamos ahora a Calzada:

me dediqué á su traduccion, muy desconfiado de desempeñar acertadamente el intento, por conocer quanta destreza necesita un traductor para verter en su lengua nativa unas cartas familiares [...]: no obstante, pudo conmigo mas el anhelo del bien general, que el temor de la pública censura, pues siempre confié en que ésta sería moderada, atendiendo á lo sano de mis intenciones (1792: IV-V).

De todas formas, por más que no se escatimaran públicos varapalos a quienes ejecutaban sus trabajos deficientemente, la tacha no alcanzaba, por supuesto, a la totalidad de quienes se afanaban en ese quehacer traductor. Además, comprendido lo irrealizable que a menudo resulta una traslación enteramente ejecutada al pie de la letra, se erigía el seguimiento más cercano posible al original en el objetivo predilecto del crítico riguroso ${ }^{5}$.

Incluso más, un traductor competente es reputado como modelo de ilustración y conocimiento. Por eso el propio Ranz Romanillos, que no dudaba en denostar a los ineptos, gusta de elogiar a los bien capacitados: "nunca se os podrá permitir que culpeis á solos los Traductores, y mucho menos que intenteis desacreditar su laborioso empleo, lleno de tédio y de penalidad, pero util al mismo tiempo, y digno de los hombres mas instruidos, ó propio, por mejor decir, de solos ellos" (1786: 33-34).

\section{Calidad y servicio a la sociedad como pretextos para traducir}

La labor traductora de García Malo tuvo su inicio en 1786, esto es, prácticamente en los albores mismos de su carrera literaria, y su final en 1811, pocos meses antes de su muerte. Idéntica amplitud se puede predicar respecto de los géneros abordados, pues lo mismo vertió al castellano prosa moral o política, como la Escuela de costumbres (1786), El Plutarco de la juventud (1804-05) o La política natural

\footnotetext{
5 Por ese camino va el sentir de Capmany: "No por esto pretendo que un traductor se sujete á trasladar palabra por palabra, sino que conserve la calidad, y fuerza de ellas" (1776: V).
} 
(1811), que poesía épica, tal que la Ilíada (1788), teatro, cual El Demofoonte (1791), o ya una novela en ocho tomos: Pamela Andrews (1794-95). La diversidad, conforme puede observarse, se extiende también a los países origen de sus fuentes, si bien con un notable predominio respecto del idioma francés, del que traslada los tres primeros títulos enunciados, así como la obra de Richardson, cuya transcripción efectúa a través de la que se considera realizada por el Abate Prévost ${ }^{6}$.

Como hemos señalado anteriormente, muchos autores solícitos con su estima literaria recelaban de verter a nuestra lengua obras extranjeras, por miedo al vituperio y a la mala opinión generalizada que imprimía el ser diplomado de traductor. Por tal razón, García Malo que sin duda se encontraba en esa tesitura de velar por su reputación como escritor $\mathrm{y}$, a la par, de colocar al alcance del lector hispano libros que creía podían contribuir al provecho general ${ }^{7}$, procurará lanzarse a la arena de la traducción adoptando diversos tipos de precauciones. Entre tales tácticas, y en sintonía con lo anteriormente apuntado por Calzada, destacan especialmente dos: por un lado, el hábito de detallar y poner en valor el trabajo y cualificación que tal menester conlleva, $y$, por otro, el cuidado en pregonar los beneficios que para la sociedad suelen derivarse del buen hacer en ese campo.

Respecto del primero de estos dos puntos, puede traerse ahora como ejemplo su extenso prefacio a la traslación de la Ilíada (noventa páginas de "Discurso preliminar", amén de otras 6 anteriores de la "Dedicatoria" con la que se inauguraba el libro), que García Malo aprovecha para paliar futuras e hipotéticas críticas, escudándose en un pretexto bastante socorrido, tal cual resulta el ponderar la extrema dificultad de la empresa a la que hubo de enfrentarse, con el argumento "de ser imposible trasladar á ningun idioma moderno el valor de las expresiones Griegas, que pintan de un solo rasgo lo que exîge muchas palabras en los de todos los demás Pueblos" (t. I, V). Unas páginas más adelante (XVIII) abundará en el tema:

Todas las lenguas tienen sus frases peculiares, y su respectiva armonía (particularmente la Griega y la Latina) y el copiar sus primores en otra, y mas siendo verso a verso, es la empresa mas dificil aun para los mayores ingenios, pues no es posible tasar las sílabas de unos versos con otros, ni por mas cuidado que se ponga, coger un verso de una lengua, y mucho menos de la Griega y Latina, y trasplantarlo en otra con su misma cadencia, expresion y armonía, como se trasplanta una mata de Claveles desde un Jardin á otro.

En apoyo de lo que acaba de argüir, García Malo busca acto seguido amparo en la autoridad del padre Isla: "No lo digo yo esto, pues el docto P. Isla en su Prólogo á la traduccion del Compendio de la Historia de España, lo explica difusamente, y

\footnotetext{
6 En modo alguno era excepcional este ejercicio de traer al castellano libros ingleses a través de su versión francesa, sino que, por el contrario, según afirma Buigues, resultaba ser práctica bastante habitual; así, en su examen de traducciones a nuestro idioma de obras inglesas en esa época, advierte este: "Dans la plupart des cas (37 éditions), l'ouvrage est d'abord traduit en français puis en castillan” (2002: 110).

7 Aparte, por supuesto, de que podía erigirse, esta de la traducción, en una vía muy eficaz para la obtención de ingresos económicos.
} 
en él se encontrará todo curioso razones tan poderosas, que convencen al entendimiento mas obstinado" (XVIII-XIX). Por otro lado, aquella singular lengua, "magestuosa, armoniosa, significativa, abundante, hecha casi á propósito para la Poesía" (XII-XIII), cuando es "manejada por el primero y el mayor de todos los Poëtas, es quasi imposible, ó imposible del todo, trasladar á otro idioma su elevacion, hermosura, expresion y grandeza" (XIII); sobre todo tratándose de la Ilíada, "obra, sin disputa, mas dificil de traducir que ninguna otra" (XIX).

También pretende conjurar el tópico de que se asocie su labor como traductor con la del escritor holgazán que, ignorando toda labor metodológica previa por evitar exprimir su minerva, se beneficia, sin rigor alguno, del talento y esfuerzo de otro: "Junté los mejores comentarios y traducciones de diferentes idiomas, y aprovechandome de sus observaciones y trabajo, y consultando á algunos sugetos hábiles en la materia, me resolví á continuar en verso mi traduccion, arreglandome en lo posible al original" (II). Esta última reflexión resultaba, además, necesaria para consignar su capacidad de desenvolvimiento en la lengua griega. Así, en otro lugar del mentado "Discurso preliminar" dejará caer también tal puntualización: "Es necesario ver el original para percibir todo el primor de este razonamiento" (LXXIV).

Por todo ello, sin duda que a García Malo debió depararle enorme alegría el espaldarazo recibido por un perito en la materia tan cualificado como Casimiro Flórez Canseco, célebre catedrático de Lengua Griega de los Reales Estudios de San Isidro, quien actuando de censor gubernativo de esta traducción de Malo no se limitó únicamente a aprobar su publicación, sino que se detuvo también en formular determinadas opiniones artísticas, todas ellas laudatorias:

Nuestros Literatos no habían emprehendido hasta ahora la traducción de la Iliada", pero a pesar de los enormes inconvenientes de traspasar la lengua griega a cualquier otra, "por la armoniosa melodía de sus versos [...], el Traductor se ha desembarazado de ellos con felicidad [...]. De manera que los que no puedan leer a este Poeta en su lengua, encontrarán en esta Traducción lo que basta para formar una buena idea de su profundo saber, y de aquello sublime y marabilloso que caracteriza sus Poesías 8 .

Similares considerandos de prólogo galeato al de su traducción de la Ilíada los hallamos en el "Discurso preliminar" a su transvase al castellano de El Demofoonte, de Metastasio, por medio del cual se vale para explicar cómo se animó a transcribir esta obra de su admirado abate italiano porque no juzgaba dignas las dos versiones anteriores por él conocidas": "ni una ni otra podian comparecer en nuestro teatro, de modo que se representase, por decirlo así, con el mismo vestido y galas

\footnotetext{
8 Archivo Histórico Nacional, en adelante: AHN, Consejos, 5553-87.

9 Una de ellas era la versión de Ramiro Díaz Sirigo: Comedia nueva. El Demofonte [sic]. Sevilla, s.a.; y creemos que la segunda se trataba de una edición publicada en Madrid, por los Herederos de Lorenzo Mojados, en 1755 (aunque D. Ignacio la feche, por error, en 1750): El Demofoonte. Drama para música de representarse en el regio coliseo del Buen Retiro [...].
} 
que la adornó su Autor, ó á lo ménos de forma que no desdixese de ser hija suya [...]. Con este objeto la he traducido ${ }^{10}$ " (1791: XIII).

Por eso, fundado en la seguridad que le confería su dominio de la lengua italia$\mathrm{na}^{11} \mathrm{y}$ en la libertad de no haberse comprometido con un esquema rígido, rotundamente vindica la superioridad de su versión frente a las otras a las que alude: "qualquiera observará que me he acercado al original, y conservado su belleza, energía, voces y armonía mucho mas que los que hasta ahora han traducido algun Melodrama de este Poeta, pues por no hacerlo en versos pareados o asonantados se han desviado mucho de una traduccion literal" (pp. IX-X).

Además, con tal de dejar constancia sobrada de su mérito en el oficio, no sentirá pereza ninguna por irnos desmenuzando detalladamente diversos aspectos de la mecánica que empleó:

he procurado no añadir ni quitar palabra alguna, quando la necesidad no me ha obligado á hacerlo para sacar un verso nuestro [...]. Para traducir este dístico literalmente no hay equivalentes palabras en nuestro idioma [...]. Además, según las sílabas que tiene este dístico, no cabe traducido en otro nuestro, y por lo mismo lo he puesto de este modo [...].Y esto mismo he practicado en los demas versos que, ó por las ménos sílabas, ó por las licencias poéticas del idioma Italiano, no es fácil hacer que salgan iguales en el nuestro con las mismas palabras (IX) ${ }^{12}$.

Curiosamente, uno de los argumentos que utiliza para ensalzar su meticulosidad y tesón en la tarea traductora de Pamela Andrews es justamente el contrario al anteriormente expuesto; porque ahora lo que se propone recalcar es el trabajo que supuso adaptar, es decir, transformar -y no meramente transcribir de forma mecánica al castellano el texto original ${ }^{13}$ - una obra de problemática publicación en España en su

10 García Garrrosa y Lafarga hacen referencia a esa precisa circunstancia: "La mala calidad de la versión existente, o la actuación muy libre del traductor con respecto al original, son los motivos que mueven, por ejemplo, a Ignacio García Malo o a Agustín García de Arrieta a sus nuevas versiones, más fieles y ajustadas al texto de partida, del Demofoonte de Metastasio o de El Espíritu del Telémaco de Fenelón, respectivamente" (2004: 64).

11 Extremo que con tacto y esmero se encarga de participarnos: "Conozco muy bien que es muy dificil copiar muchas gracias de la lengua Italiana, y trasladar un verso de ella con las mismas palabras en otro igual que en la nuestra" (1791: VIII-IX). Además, según él mismo nos desvela, su propia carrera literaria la "empezó en Roma desde muy joben" (AHN, Estado, 3566-33).

12 De ahí que, a cuenta de tanta minuciosidad, Andrea Baldissera pueda decir de nuestro autor que "adopta una perspectiva de fidelidad al texto, hasta filológica" (2007: 160). Y es que toda reserva al respecto era poca, especialmente tratándose de traducciones de Metastasio, donde por mor de las circunstancias parecían cebarse más en esos sus vicios quienes las trasladaban; Joaquín Arce lo resume así: "El melodrama metastasiano no sólo es elemento que debe considerarse en la historia de las costumbres, sino que produjo deletéreos efectos para la lengua española a juzgar por la reacción de los puristas y los lingüistas del siglo XVIII. Entiéndase bien que el mal es atribuido a todo género de traducciones. Pero la abundancia, persistencia y apresuramiento con que tendrían que ser hechas las versiones melodramáticas para publicarlas solas o en ediciones bilingües, hace de estos libretos el principal punto de mira de los ataques" (1981: 89).

13 García Malo en ningún momento admite que su fuente sea la versión francesa, aunque sí que alude a ella, tal vez para hacer ver que también la manejó: “Así en el original como en la traduccion francesa viene el siguiente artículo" (1799, t. I: VII-VIII). 
estado primario: "pero ó sea porque las costumbres de Inglaterra estan mas corrompidas que las nuestras, ó porque la índole de la lengua inglesa admite ciertas expresiones é idiotismos que sonarian mal en la nuestra, hemos juzgado oportuno reformarlas ó suprimirlas ${ }^{14}$ "' (II-III).

Tantos cuidados lingüísticos, literarios y hasta sociales, y sobre todo la explícita proclamación de una escrupulosa y pulcra ejecución de los mismos, habían de proporcionarle el suficiente alejamiento anímico e intelectual respecto de toda aquella caterva de traductores que, sin particular recato, traían al español producciones foráneas, en una labor cuasi industrial de importación.

Tal praxis le sirve, en fin, para ser incluido en un selecto elenco, en el que su nombre, conforme a aquella tan perseguida aspiración suya, figura apartado de la plaga de descuidados e indolentes dragomanes. Así lo reconoce Lafarga:

Los nombres de Tomás de Iriarte, Gabriel Antonio de Borbón, Clavijo y Fajardo, Ranz Romanillos, Goya y Muniain, García Malo, Saviñón, Javier de Burgos, entre otros, ayudan a esbozar el perfil de un traductor serio, riguroso, cada vez más consciente de la formación, cualidades y método que requiere su trabajo. Una imagen que contrarresta el retrato satírico de la denigrada actividad de traductor (2004: 227).

Otro argumento significativo, para justificar la misión de convertir al castellano textos de otras lenguas, halla su asiento en la devoción del siglo hacia aquello que pueda resultar provechoso, especialmente cuando dicha cualidad sea susceptible de beneficiar al conjunto social. Así puede aseverar Álvarez de Miranda que: "Todas las cuestiones se miden en la Ilustración con el rasero de lo útil", y que "los adjetivos que más frecuentemente acompañan a utilidad son por este orden, pública y común" (1992: 306 y 307).

García Malo no podía en modo alguno desaprovechar este filón, por más manido que resultase $\mathrm{e}^{15}$; de ahí que en su conversión de la Ilíada lo espeta in promptu, a las primeras de cambio, y en la misma "Dedicatoria" (compuesta de seis páginas sin numerar) al conde de Floridablanca que antecede al "Discurso preliminar", cuando habla del: "deséo de emplear mis cortos talentos en utilidad de la patria". Y fundamenta, acto seguido, esta iniciativa suya en varios puntos, entre otros, por ejemplo, en el propósito de acercar los textos clásicos a quienes no entienden la lengua en que están escri-

14 De todas formas, se hace menester indicar en este punto que en ninguna de las dos ediciones en que aparecieron los ocho tomos de Pamela (1794-95 y 1799, respectivamente), consta en ellas el nombre de nuestro escritor. Atribuimos su silencio a causas extraliterarias, en las que no nos podemos ahora detener. Pero aun así, suponemos que si bien para el general del público resultaba anónima la traslación, quizá no lo fuera tanto en el círculo en el que él se movía, esto es, en el colectivo de los entendidos en la materia, precisamente al que mayor temor mostraban los traductores; razón por la que Malo, aun incógnita su identidad, no pudiera bajar la guardia.

15 Así lo expresan García Garrosa y Lafarga: "Se convirtió en un tópico el que los traductores declararan en sus prólogos que la primera razón para tomar la pluma había sido no privar por más tiempo al público español de obras que, por sus méritos literarios o por sus valores morales, gozaban ya de gran fama en toda Europa. Pero como todos los tópicos, no carecía de fundamento" (2009: 39). 
tos, o el de formar el gusto literario de modo que otros se aficionen a lo sublime. Todo ello con la intención de ser exonerado de posibles recriminaciones, pues según manifiesta, en remate de su alegato, confía en que los reseñados objetivos "pueden disculpar mi temeridad, y no hacerme indigno de la indulgencia del Público".

Méritos esos que le son reconocidos por el propio censor, el referido Flórez Canseco:

Siendo pues esta la primera Traduccion de la Yliada que se publica en Castellano, $\mathrm{y}$ en la que por las grandes dificultades de que he hablado no puede menos de haber puesto el Traductor mucho trabajo, y consumido mucho tiempo; y siendo ademas esta obra de una utílidad notoria por lo muchisimo que puede contribuir su lectura a formar el buen gusto en este bello ramo de literatura, y dar a los Jovenes una verdadera idea de la solida eloquencia, me parece muy acrehedor el Traductor, à que se le dè la licencia que necesita, para su impresión ${ }^{16}$.

En cuanto a la mencionada traducción de El Demofoonte, tampoco abandona García Malo ese deseo de proclamar sus pretensiones didácticas, orientándolas ahora a perfeccionar el entendimiento literario y crítico del lector-espectador, y supeditando precisamente una probable continuación en su labor traductora de Metastasio al logro de este objetivo:

Si este ensayo ó pensamiento mio fuese grato al público, y propio para mejorar el gusto de nuestro teatro, y el estilo poético dramático que debe usarse en él, y aquel trágico mas capaz de excitar la sensibilidad, el terror, la compasion y la suspension del auditorio, me dedicaré á traducir en la misma forma algunos otros Dramas de este Poeta (1791, XIV).

Por lo que atañe a su adaptación de Pamela, aparte de las consabidas manifestaciones sobre los irrenunciables fines de utilidad pública ${ }^{17}$, García Malo, prevaliéndose de que se trata de una novela epistolar, aprovecha para añadirle un valor más, bastante original por cierto, y centrado en el ámbito educativo:

podrá servir de modelo del estilo epistolar, de que nuestra juventud tiene tanta falta; pues hay muchachos, y aun hombres de veinte ó veinte y cinco años, que despues de haber salido de los Colegios y Universidades, todavia no saben dictar una carta ni contar lo que les pasa con precision, claridad, facilidad y sencillez. ¿Y por qué? Por la falta de lectura de libros de esta especie; cuyo defecto es mucho mas comun en la educacion de las mujeres.

Para concluir este punto, ha de observarse que la obsesión de remarcar de manera prominente en sus traducciones las dos señaladas circunstancias: empeño personal de

16 AHN., Consejos, 5553-87.

17 "He aquí el objeto de nuestra traduccion: presentar al publico un modelo de modestia y de virtud" (1799, t. I: II). "El norte de todo escritor debe ser siempre el bien general de sus conciudadanos, cuidando de publicar obras que edifiquen en lugar de destruir [...]. El objeto de esta historia no puede ser mas útil en el fondo" (1799, t. V: VI). 
aplicarse con esmero y exigencia profesional, por una parte, y razones de aprovechamiento para el lector y para la sociedad, por otra, bien patente en las anteriores tres obras de ficción, se ve reducida solo a la segunda de ellas cuando vierte libros de tipo instructivo o didáctico; como si ya la propia materia trasladada sirviera para "redimirle" al menos en parte de ese pecado original que parecía acompañar a los traductores. Sirva de muestra un ejemplo por cada uno de los libros de esta especie:

El deseo que tengo del bien, y utilidad del público, la que puedo firmemente esperar reproducirá esta sàbia obra à los jovenes, y a toda clase de personas ${ }^{18}$.

Este es en bosquejo el quadro que ofrecemos á la juventud española, deseosos de contribuir, en quanto alcanzan nuestras fuerzas, á su mejor educacion, fundamento de todas las virtudes; y con este objeto hemos suprimido algunas vidas, de cuya lectura nos ha parecido que no sacaría el fruto que nos proponemos y esperamos con alguna confianza ${ }^{19}$.

La Politica natural que contiene este corto volumen es una de aquellas obras que pueden contribuir mucho á tan importante fin [el bien general] (García Malo 1811b: VII).

\section{Teoría frente a práctica en la introducción de neologismos}

Si por un lado el hábito de traducir acompañó a D. Ignacio durante toda su vida literaria, por otro también nos consta que la lengua, en abstracto considerada, había resultado objeto de profundas reflexiones por su parte; una buena prueba de ello lo constituye la polémica que, sobre el eusquera, sostuvo con Astarloa en Variedades de Ciencias, Literatura y Artes y, posteriormente, en el Mercurio de España, en donde nuestro autor se decantaba claramente por la convencionalidad de los idiomas ${ }^{20}$.

Otra muestra de su dedicación por el tema del lenguaje, así como de la importancia enorme que presta a la poderosa autoridad de los vocablos, lo encontramos en alguno de sus libros políticos:

Quanto mas exâminemos esta qüestion, mas nos convenceremos de que la inexâctitud en las voces produce inexâctitud en las ideas, y quando en estas hay

18 García Malo 1786, t. I: III. Ya desde el mismo título se avanza la referida intención de utilidad: Escuela de costumbres [...]. Obra útil a los jóvenes y a toda clase de personas para conducirse en el mundo [...]. Como al igual ocurre en la obra a que nos referimos en la nota siguiente: Plutarco de la juventud [...]. Obra elemental, propia para elevar las almas de los jóvenes e inspirarles las virtudes más útiles a la sociedad [...].

19 García Malo 1804, t. I: VIII-IX. En este caso, además, el beneficio social que el libro puede producir se halla corroborado tanto por el censor eclesiástico de la obra, como por el civil, José Gómez Hermosilla, catedrático de Retórica de los Reales Sitios, en el expediente para obtener la licencia de impresión (AHN, Consejos, 5566-42, s.n.).

20 García Malo, con el seudónimo de Gil Cano Moya, rebate a Pablo Pedro de Astarloa la existencia de lengua alguna capaz de significar conceptos solamente por sus sonidos, sin recurrir a un pacto entre los hablantes (1805: 153-154). 
confusion, no es estraño que aun queriendo todos una misma cosa, no nos convengamos en ella por la diversa acepcion que damos á las palabras (García Malo 1810: 10).

Pocas páginas después (23), adornará el asunto con una síntesis rotunda: "no equivoquemos las ideas, como antes he dicho, por no definir bien las palabras". Ya desde la misma "Advertencia", con la que se abre la obra, nos había declarado Malo esa inquietud. Y así, para justificar el trasplante, tal cual, de ciertas locuciones halladas en diferentes autores, arguye: "porque usando de otras expresiones ó lenguage me esponia á apartarme del camino de la verdad" (h. s. n.). Es decir, el error o la certeza dependerá en gran medida de la elección de los términos utilizados.

Tales preocupaciones gramaticales le llevan, incluso, a reprender públicamente a quien hace mal uso del ejercicio lingüístico:

Pero esta cuestion es mas honda de lo que puede comprehender un militar, que confiesa no saber ortografia, ni elocuencia por no haber estudiado ni una ni otra, aunque se precia de entender el castellano rancio y no el producido por estos ingertos modernos. En esto no habrá quien desmienta á V.: su misma carta lo está diciendo, y sin ir muy lejos, á la cuarta linea, donde hay un pero sin madurar $^{21}$, que dá muy bien a conocer el arbol que le há producido (García Malo 1811a: 1-2).

Por ambas circunstancias: incesante actividad traductora y conciencia de la importancia del idioma como elemento de unificación social, puede erigirse la figura de nuestro autor como muy a propósito para ejemplificar las glorias y miserias, pero sobre todo las paradojas, en las que frecuentemente se desenvolvía dicho menester de traducir.

En lo relativo a su propia historia personal, su prolongada experiencia en el ámbito de la traducción apunta a una trayectoria que va de posiciones más estrictas hacia otras más tolerantes, al menos en lo que concierne a la utilización de neologismos, si bien ya desde temprano nos encontramos con alguna que otra contradicción. Tómese, en prenda de ello, el rígido criterio que mantenía hacia finales de los años 80 y 90, según parece deducirse de la contestación de Juan Clímaco de Salazar a la carta (cuyo contenido ignoramos) remitida por Malo comentando el Mardoqueo: "En lo que me dice Vmd. de algs. particulas, articulaciones y palabras italianizads. no tendria yo tanto escrupulo ${ }^{22}$, u otra aseveración posterior en la que, en la

\footnotetext{
21 Se apoya el juego de palabras en una conjunción "pero" que, sin venir a cuento, introduce "el Ciudadano Militar" allí justamente donde precisa García Malo.

22 Citamos por una fotocopia - de otra suya, amablemente facilitada por John Dowling- de una carta de Juan Clímaco de Salazar a García Malo, escrita hacia 1788 o principios de 1789. El original, perteneciente al Archivo de Rodríguez Moñino, se conserva hoy en la Real Academia Española. No podemos dejar escapar este episodio entre Salazar y Malo sin hacer una referencia al tono de desenfado del primero, cuando en una carta a Forner, fechada en Roma el 21 de octubre de 1789, y en relación con el envío de su Mardoqueo a Joaquín Ezquerra y a García Malo para que lo examinaran antes de darlo a la estampa, comenta, jocoso, lo siguiente acerca de las innumerables correcciones propuestas por estos: "Considere Vmd. como estarè yo
} 
"Advertencia del traductor" a la Escuela de costumbres, efectúa la siguiente declaración ${ }^{23}$ :

He procurado hacer esta traduccion con la posible exactitud y escrupulosidad, tomandome alguna licencia en la version de ciertas frases nacionales, para acomodarlas á la expresion de nuestro idioma, sin quitarles su propio vigor y sentido, ni cometer galicismos, pues nuestra lengua no necesita mendigar las palabras, siendo como es tan abundante, eloquente y rica ${ }^{24}$.

Un nuevo indicio de este talante academicista o de disciplina formal que, al menos en su fuero interno, pretendía mantener en sus traducciones, se infiere de la nota que sigue a las "Reflexiones particulares sobre la educación", dentro del tomo IV de la susodicha Escuela de costumbres:

Questa, que vá repetida en este Discurso varias veces, significa según nuestro Diccionario, mendicidad, peticion, y recogimiento de dinero con autoridad públi$\underline{\mathrm{ca}}$, por razon de Religion, \&. Y como el Francés dice el equivalente quete, lo he usado en lugar de colecta de limosnas, ú otro igual de que pudiera haberme valido; y tambien questor, que es el que demanda, ó pide limosna (1786: 294).

De ahí que podamos hablar de paradojas o discordancias, porque, curiosamente, el censor Cayetano de la Peña no dejará de advertirle que debía subsanar algunos de dichos extranjerismos, detectados precisamente en el segundo volumen de este último libro citado: "encargando al traductor corrija algunos galicismos, dandoles toda la propiedad de nuestro idioma, pues ha sabido superar maiores dificultades en la version del verso 25 ".

Esta -aunque, según se ve, más bien teórica- actitud rigurosa respecto de la inserción de neologismos puede compararse con aquella otra, si no autocomplaciente, mucho más flexible y despreocupada de 1804, cuando a raíz de presentar su traducción de El Plutarco de la juventud, declara: "confesamos con ingenuidad que, aunque hemos procurado evitar galicismos, y no emplear frases ni palabras que no convengan con la pureza de nuestro idioma, no nos lisonjeamos de haber conseguido, en esta parte, todos nuestros deseos" (1804, t. I: XI-XII).

ya del Mardocheo despues de un año de ser machacado y machacar sobre su accion, sobre su diccion, sobre sus [ilegible en nuestra copia], sobre sus galicismos, sobre sus italianismos. Si yo estubiera tan arrepentido de mis otros pecados como lo estoy del pecado de haber enviado mi tragedia a Madrid estarìa quasi seguro de mi justificación y eterna bienaventuranza" (Biblioteca Nacional de Madrid, Ms. 21885, ff. 92r. y 92v.).

${ }^{23}$ García Malo (1797, t. I: XX). Aunque la primera edición de este libro data de 1786, el referido prólogo de Malo no apareció hasta la segunda impresión: Madrid, tomos I y III de Villalpando, II y IV de la Viuda e Hijo de Marín. Por lo demás, con la rara excepción de haber mutado algún que otro término, ambas versiones son prácticamente idénticas.

${ }^{24}$ De todos modos García Malo no llegó nunca a los extremos que Martinell observa en gran parte de los coetáneos de aquel: "Ofuscada [la mayoría de los autores] por el orgullo de la propia lengua, ataca despiadadamente a la lengua francesa, como si no fueran los mismos españoles los que emplean galicismos en sus frases y escritos" (1984: 106).

${ }^{25}$ AHN, Consejos, 5552-54, h. s. n., expediente para obtener licencia de impresión. 
Y si por un lado se enorgullece de haberse "acercado mas que quantos me han precedido á una version literal del Demofoonte" (1791: IX), por otro, no siente empacho ninguno en reconocer que ha efectuado cambios por "necesidad", así como que ha amputado pequeños fragmentos que "nada contribuyen al interes de la accion" (1791: XIII-XIV). Del mismo modo que, ya en tiempos anteriores, había alterado los pasajes de la referida Escuela de costumbres que estimó oportunos, o cercenado después, inmisericorde, en Pamela Andrews todo aquello que por razones morales o literarias reputó como inadmisible ${ }^{26}$ :

Que esto se diga ó no con las mismas expresiones, y aun con los mismos episodios, importa poco para la moralidad que se pretende sacar [...]. Por consiguiente sería mucha lástima que careciésemos de esta historia en nuestro idioma, por no reformar en el original las cosas accidentales que se oponen á nuestras costumbres y modo de pensar ${ }^{27}$ (1799: t. I: II-III).

En ese sentido, la mentalidad del momento jugaba a favor de dicho fenómeno de adaptar lo foráneo a lo patrio, pues como señala García Garrosa: "Las convenciones de la época daban por buenas todas las "manipulaciones", tanto ideológicas como lingüísticas, que el traductor quisiera operar en el texto original si con ello conseguía un nuevo texto más acorde con el sentir y el carácter nacionales" (1992: 45).

De lo expuesto no se puede colegir tampoco que García Malo cometiese menos galicismos en su época primera que en las posteriores, puesto que, presentes ellos a lo largo de toda su carrera literaria, resulta más lógico suponer que, quizá llevado de las prisas en sus traducciones iniciales o menos avezado en la técnica del traslado idiomático, no se percatara entonces de muchas de estas incorrecciones lingüísticas. Y, para la gráfica constatación de que tal fenómeno lo acompañó a lo largo de su existencia, vayan ahora, a título simplemente ilustrativo, unos cuantos de tales deslices, fruto de un rastreo por su obra de ningún modo exhaustivo: "se esfuerze à persuadirselo" (1786, t. I: 6), "somos deudores à su nombre" (418), "obligante" (420 y 425), "no mezcles las reprensiones à tus beneficios" (421), "se encantó de" (427); "cria diversamente a su hijo" (1797, t. IV: $162), “ i[\ldots]$ hay tampoco verdadera moral sin ella?" (172), [un hecho] "á corregir muchas madres" (183), [un domicilio] "fue fixado á Blois", "no hacer a él ninguna atencion" (196), "sin creer que se piense á él" (197), "ser los primeros á destruirlos" (206), "continuais á juzgar con él" (210), "mezclad siempre á vuestras lecciones iguales exemplos" (234), "lo instruia á no poner" (270).

Mención aparte debía sin duda merecer el tomo II de esa misma Escuela de costumbres en su forma primitiva, la cual habría de contener tal número de francesis-

${ }^{26}$ El propio título señala dicho extremo: Pamela Andrews o la virtud recompensada: escrita en inglés por Thomas [sic] Richardson. Traducida al castellano: corregida y acomodada a nuestras costumbres por el traductor, $1^{\text {a }}$ ed., Madrid, Antonio Espinosa, 1794-95.

${ }_{27}$ Así, con razón puede ser encuadrado García Malo por Eterio Pajares dentro de la "corriente renovadora-imitadora", junto a escritores como Trigueros, Calzada, Valladares, Izco, etc. (1996: 170). Más recientemente, el mismo Pajares Infante (rescatando la expresión de trabajos suyos anteriores) calificará dicho fenómeno como "traducción tutelada" (vid. 2010: 63-72). 
mos que hasta el propio censor, como ya pusimos de manifiesto, efectúa reproche por ello (única protesta, por cierto, de Cayetano de la Peña respecto de este particular en todas las obras de García Malo sobre las que le tocó emitir dictamen). Porque resulta que, así y todo, y suponemos que tras eliminar una buena parte de tales neologismos, nos encontramos aún con un buen puñado de ellos: "obligante", en vez de "amable" (224), "hacer tu deber" ("faire votre devoir"), por "cumplir con tu deber" (239), "decia á este asunto" en lugar de "sobre este asunto" (250), "continuamos á instruir" (245), "comprar á todo precio" ("à tout prix"), "creyendo abatir en él" ("croyant abattre en lui"), por "creyendo abatir con él" (254). Y todo eso sin tener en cuenta expresiones de cortesía como "monsieur" (231), "madama" (256), o palabras originarias del francés, pero admitidas en el castellano: "jarrete" (211).

Por lo que respecta a Pamela Andrews, entresacamos los siguientes giros o términos procedentes, asimismo, del francés: "confiar del hijo" (1799, t. VIII: 181), "á este modo" (182), "se instruiría de" (183), "los jovenes que se destinan [dedican] a viajar" (184), "juzgar de" (184), "conciliarla [granjearla] enemigos" (191), "traerlo á conversacion" (193), "á [de] no haber creido" (196), "admirarse á sí mismos á un espejo" (199), "apasionado á este estilo" (201), "ocupados en hacer la aplicación á sí mismas" (203), "pero", en vez de "sino" (221).

También copiaremos aquí varios galicismos concernientes a la versión publicada de El Plutarco de la juventud: "salió [...] á campaña" (t. VI: 160), "que pudieran tener á [en] la España" (170); (cit., t. VII): "impedir [abstenerse] de" (254), "variado á lo infinito" (257-258), "le arrebató á las letras" (278), "en vez de que [a la vez que]" ( 280). Y gracias a los ejemplares manuscritos que, de diversos tomos de esta obra, se guardan en el Archivo Histórico Nacional llegamos al conocimiento de otros extranjerismos del mismo origen, inéditos por haber tachado la censura el texto al que pertenecían: "perfectamente [de forma perfecta]" (AHN, Consejos, 50833-614, t. I: 45r.), "le inspiró el gusto á la poesia" (AHN, Consejos, 5784, t. V: 92), "dexó á Paris" (94), "abandonar á Paris" (97), "reconocido á [por] este ligero beneficio" (126).

Para poner fin a tan tediosa relación, queremos anotar solo unos cuantos galicismos advertidos en La política natural, la postrer traducción de nuestro autor: "concurrentes [competidores]" (1811b: 28), "reusa [niega]" (36), "deciden de las recompensas" (42-43), "aplaudirse de [felicitarse por] la necesidad" (74), "juzgar de la justicia [juzgar la justicia]" (81).

Si tomamos como referencia esta sucinta compilación, podría plantearse también otra hipótesis para explicar la divergencia entre sus postulados teóricos y su realización práctica, esto es: que su estricta actitud frente a los neologismos (reconocida por él y declarada por algún amigo suyo, como Salazar) estuviera focalizada únicamente en los vocablos, y no se extendiera a los modismos o giros propios del francés, pues ha de convenirse en que los primeros aparecen en muchísima menos proporción que los segundos ${ }^{28}$.

28 A este respecto anota Antonio Rubio: "Los galicismos eran de léxico o de sintaxis y, a veces, mixtos. El análisis sintáctico o del estilo requiere una prudencia y una objetividad consumadas. El galicismo en este orden es difícil de estudiar y reconocer" (1937: 209). 
De otra parte, y por lo que toca a los italianismos, debe reseñarse que estos carecieron de relevancia alguna en su obra, pues en la única composición suya traída de la lengua de Dante, El Demofoonte, apenas un par de ellos asoman a sus páginas ${ }^{29}$. En cambio, si que cae en un solecismo, y no de los menores, al escribir "tú me desprecia" (I, $6^{\text {a }: ~ X X X V I I I), ~ e n ~ l u g a r ~ d e ~ " d e s p r e ́ c i a m e ~ t u ́ " ; ~ e r r o r ~ a d e m a ́ s ~ b i e n ~ g r a t u i t o, ~}$ pues ni siquiera está originado en la búsqueda de una determinada rima.

\section{Conclusión}

A pesar de todas las deficiencias apuntadas -las de García Malo y las de otros de sus contemporáneos-, y por encima de los defectos, imprecisiones, lagunas o deterioros que pudieran derivarse del mester de traducir, es cosa cierta que gracias a dicha práctica una corriente de aire fresco entró en el viejo solar hispano, modernizando las letras españolas, como ya Sempere y Guarinos temprana y sagazmente observó $^{30}$, y tiempo después, con la perspectiva de los años, Menéndez Pelayo se encargó de sancionar con el siguiente veredicto: "Todas estas tentativas, por raquíticas y desmedradas que parezcan, no podían menos de modificar de alguna suerte el carácter de nuestra literatura de fines del siglo XVIII, haciéndola cada día más europea y cosmopolita, y llevándola por nuevos rumbos" (t. III 1947: 395).

Siempre al quite con rendir fructíferos servicios a su país, el campo lingüístico no habría de constituir un escollo para un escritor cualificado y conocedor de varios idiomas, como fue el caso de García Malo; por eso buscó extraer, de allí donde se encontraban, los saberes de los que carecíamos en castellano, y, aun siendo consciente de los riesgos que tal actividad podía entrañar para su reputación literaria, se aplicó en traducir para sus compatriotas diversas obras extranjeras que consideraba que debían ser aprovechadas en España.

Hemos de subrayar, finalmente, que la convicción de García Malo de que la lengua española era tan admirable como la que más lo llevó a componer una ópera, Glaura y Cariolano, con el fin de demostrar la capacidad del idioma hispano para la música, así como para proclamar su legítima aspiración de crear un teatro lírico a semejanza del italiano:

esta piececita es solamente un ensayo en nuestro idioma Castellano de la grande Opera seria Italiana [...], únicamente con el objeto de demostrar que nuestra Lengua es capaz de las modulaciones de la Música, y que podemos aspirar á formar

29 Identificamos ahí como inequívocas locuciones italianas "annuo" (por anual) que acompaña a "sacrificio" (I, 2: XXIII, y III, 12: CIII), así como la nominación "Jove" ("Giove” en el original) para el dios Júpiter (I, 13: XLVIII).

30 "La mayor parte de los Traductores de lenguas vulgares han afeado nuestro idioma con voces y frases nuevas, y con cierta languidez muy agena del caracter, y genio de los Españoles. Mas por otra parte la han enriquecido de ideas, y aun en quanto al estilo han contribuido á purgar éste de ciertos vicios que se habian hecho generales en nuestros libros, y ahora no lo son ya tanto, qual es el de la hinchazón, sutileza, cadencia, hipérboles, y metáforas de que antes estaban empedradas las obras aun en los mas sabios escritores" (Sempere y Guarinos 1789, t. VI: 230). 
con el tiempo un Teatro Lírico, imitando á los Italianos, como han procurado hacerlo los Franceses, no obstante que su lenguaje ni es tan numeroso, ni armonioso como el nuestro ${ }^{31}$ (1792, “Advertencia»: h. s. n.).

\section{Referencias bibliográficas}

\section{MANUSCRITOS}

A. H. N., Consejos, 5552-54.

A. H. N., Consejos, 5553-87.

A. H. N., Consejos, 5566-42.

A. H. N., Estado, legajo 3566, expediente 33.

Real Academia Española, Archivo de Antonio Rodríguez Moñino, "Carta” de Juan Clímaco de Salazar a García Malo.

Biblioteca Nacional de Madrid, Ms. 21885.

Biblioteca Histórica de Madrid, 1-93-2.

\section{IMPRESOS}

Álvarez de Miranda, P., Palabras e ideas: el léxico de la Ilustración temprana en España (1680-1760). Madrid: Anejos del Boletín de la Real Academia Española 1992.

ARCE, J., La poesía del siglo ilustrado. Madrid: Alhambra 1981.

BALDISSERA, A., «Metastasio en España, entre traducciones y adaptaciones», Boletín de la Biblioteca de Menéndez Pelayo, LXXXIII (2007), 153-175.

Buigues, J. M., «Le traductions dans 1'Espagne des Lumières: langues, rythmes et contenus», Bulletin Hispanique, $\mathrm{n}^{\circ}$ 1, (juin 2002), 101-120.

Cadalso, J., Cartas marruecas, edición de Caso González, J. M., Madrid: Espasa-Calpe, S.A., Austral, 1952, $9^{\text {a }}$ edición, 1989.

CAlzadA, B. M., «El traductor», en: Condesa de Genlis, Adela y Teodoro, o cartas sobre la educación, escritas en francés por la -, y en castellano por el teniente-coronel D., $2^{\mathrm{a}}$ edición, Madrid: Imprenta Real 1792.

Capmany, A. de, Arte de traducir el idioma francés al castellano. Con el vocabulario lógico y figurado de la frase comparada de ambas lenguas. Madrid: Imprenta de D. Antonio de Sancha 1776.

ÉTIENVRE, F., «Le gallicisme en Espagne au XVIIIème siècle: modalités d'un rejet», en: Aymes, J. R. (ed.), L'image de France en Espagne pendant la seconde moitié du XVIII ${ }^{o}$ siècle. Alicante-París: Presses de la Sorbonne Nouvelle 1996, 99-112.

ÉTIENVRE, F., «Traducción y renovación cultural a mediados del siglo XVIII en España», en: Fernández Albadalejo, P. (ed.), Fénix de España. Modernidad y cultura propia de la España del siglo XVIII (1737-1766). Madrid: Marcial Pons, Ediciones de Historia 2006, 93-118.

31 Acerca de este drama, Santos Díez González, uno de los censores gubernativos, quizá recogiendo el guante lanzado por el autor, manifestó en su dictamen lo siguiente: "le he hallado proporcionado por su lenguaje, y suave versificacion pra. ponerse en Musica, y servir de ensayo á otros Melodramas en Castellano" (Biblioteca Histórica de Madrid, 1-93-2, h. s. n.). 
FORNER, J. P., Exequias de la lengua castellana, edición, introducción y notas de Pedro Sainz y Rodríguez. Madrid: Espasa-Calpe, S.A. 1967.

GARCÍA GARrosa, M. J., "Valladares adaptador de Marmontel. Una nueva versión española de los Contes moraux», Estudios de investigación franco-española, $\mathrm{n}^{\circ} 7$ (1992), 39-54.

GARCÍA GARrosa, M. J., «El debate sobre las traducciones en España en el siglo XVIII: un espacio de opinión pública», en: Cantos Casenave, M. (ed.), Redes y espacios de opinión pública. De la Ilustración al Romanticismo. Cádiz, América y Europa ante la Modernidad. 1750-1850. Cádiz: Universidad de Cádiz 2006, 541-554.

García Garrosa, M. J., y LAfARga, F., El discurso sobre la traducción en la España del siglo XVIII. Estudio y antología. Kassel: Edition Reichenberger 2004.

García Garrosa, M. J. y Lafarga, F., «La historia de la traducción en España en el siglo XVIII», en: Sabio Pinilla, J. A. (ed.), La traducción en la época ilustrada. (Panorámicas de la traducción en el siglo XVIII). Granada: Editorial Comares 2009, 27-80.

García Malo, I., «Dedicatoria al Excelentísimo Señor Don Antonio de Sentmanat», en: Blanchard, J. B. D., Escuela de costumbres [...]. Obra útil a los jóvenes y a toda clase de personas para conducirse en el mundo [...], traducida fielmente al castellano por D. - . Madrid: Blas Román, t. I, 1786.

García Malo, I. «Discurso preliminar», en: Homero, La Ilíada de Homero, traducida del griego en verso endecasílabo castellano por D.- Madrid: Pantaleón Aznar, t. I, 1788.

García Malo, I., «Discurso preliminar», en: Metastasio, P., El Demofoonte del Ab. Pedro Metastasio, traducido en castellano. Y representado por la Compañia de Eusebio Ribera en el coliseo del Príncipe en el año de 1791 con el título del inocente usurpador. Madrid: Benito Cano 1791.

García Malo, I., Drama heroico en verso castellano, intitulado Glaura y Cariolano. Puesto en música por D. Joseph Lidón, organista principal, y vicemaestro de la Real Capilla de S. M., y representado en el coliseo del Príncipe por la Compañia de Ribera. Madrid: Imprenta Real 1792.

García Malo, I., «Prólogo del traductor», en: Richardson, S., Pamela Andrews o la virtud recompensada: escrita en inglés por Thomas [sic] Richardson. Traducida al castellano: corregida y acomodada a nuestras costumbres por el traductor. Madrid: Antonio Espinosa, t. I, 1794.

García Malo, I., «Advertencia del traductor», en: Blanchard, J. B. D., Escuela de costumbres. Madrid, Villalpando, t. I, 1797.

García Malo, I., «Prólogo del traductor», t. I, y «El traductor», t. V, en: Richardson, S., Pamela Andrews o la virtud premiada [...]. Madrid: Imprenta Real 1799.

García Malo, I., «Advertencia del Traductor», en: Blanchard, P., Plutarco de la juventud [...].Obra elemental, propia para elevar las almas de los jóvenes e inspirarles las virtudes mas útiles a la sociedad [...], traducida al castellano por D.—. Madrid: Imprenta de Aznar, t. I, 1804.

García Malo, I. (con el seudónimo de Gil Cano Moya), «Señores editores de las Variedades», en Variedades de Ciencias, Literatura y Artes, n ${ }^{\circ} 3$, (1805), 148-159 y 230-241.

García Malo, I., Los derechos de la soberanía nacional. Contra el despotismo y la hipocresía. Palma de Mallorca: Imprenta Real 1810.

García Malo, I., Respuesta a la carta del ciudadano militar publicada en el día de ayer. Palma: Imprenta de Miguel Domingo 1811a.

García MALO, I., La política natural (traducción de La politique naturelle, ou discours sur les vrais principes du gouvernement. Par un ancien Magistrat). Mallorca: Imprenta de Miguel Domingo 1811b. 
LAFARGA, F., «La traducción en la España del siglo XVIII», Trasvases culturales: literatura. Cine. Traducción (1997), 37-55.

LAfArGA, F., «El siglo XVIII, de la Ilustración al Romanticismo», en: Lafarga, F., y Pegenaute, L. (eds.), Historia de la traducción en España. Salamanca: Ambos Mundos 2004, 209-319.

LÁZARO CARRETER, F., Las ideas lingüísticas en España durante el siglo XVIII. Barcelona: Editorial Crítica 1985.

LÓPEZ, F., «Las obras extranjeras anunciadas en la Gaceta de Madrid. Estudio diacrónico. Elementos de una estadística», Estudios de Historia Social, números 52/53, Ministerio de Trabajo y Seguridad Social (enero-junio de 1990), 303-311.

MARTINELL, E., «Posturas adoptadas ante los galicismos introducidos en el castellano en el siglo XVIII», Revista de Filología de la Universidad de La Laguna, no 3 (1984), 101-128.

Menéndez Pelayo, M., Historia de las ideas estéticas en España. Edición revisada y compulsada por Sánchez Reyes, E., t. III, siglo XVIII (2ª tirada, nuevamente corregida), Santander: Aldus, S.A. de Artes Gráficas 1947; en Edición Nacional de las Obras Completas de Menéndez Pelayo, dirigida por Artigas Ferrando, M., Madrid: C. S. I. C.

Metastasio (Pietro Antonio Domenico Bonaventura Trapassi Gallastri), traducción de Ramiro Díaz Sirigo, Comedia nueva. El Demofonte [sic], Sevilla, s.a.

Metastasio, traducción anónima de El Demofoonte. Drama para música de representarse en el regio coliseo del Buen Retiro [...]. Madrid: Herederos de Lorenzo Mojados 1755.

Pajares Infante, E., «La teoría de la traducción en el siglo XVIII», Livius. Revista de Estudios de Traducción, $\mathrm{n}^{\mathrm{o}} 8$ (1996), 165-174.

Pajares Infante, E., La traducción de la novela inglesa del siglo XVIII, Galván, F. (ed.), Vitoria: Portal Education 2010, 63-72.

Ranz Romanillos, A. (con el seudónimo de Arnoldo Filonoo), Desengaño de malos traductores: obra crítica, en que se censura la nueva versión del Poema de la Religión de Luis Racine, y se intenta contener a los que se arrojan a traducir sin los debidos conocimientos. Madrid: Pantaleón Aznar 1786.

Rubio, A., La crítica del galicismo en España (1726-1832). México: Ediciones de la Universidad Nacional de México 1937.

Trigueros, C. M., Mis pasatiempos. Almacén de fruslerías agradables, por el ultimo continuador de la Galatea, Don - . Madrid: Viuda de López 1804.

Sempere y GuARinos, J., Ensayo de una biblioteca española de los mejores escritores del reinado de Carlos III. Madrid: Imprenta Real, tomo VI, 1789.

VARgas y Ponce, J. DE, Declamación contra los abusos introducidos en el castellano [...]. Madrid: Imprenta de la Viuda de Ibarra 1793. 